\title{
14 Sachregister
}

Agentivität 95

Aktionsart (lexikalischer Aspekt) 14, 35, 37, 38, 40, 41, 44, 45, 46, 55, 59, 61, 189, 191, 194, 195, 196

Area of Interest (Aol) 106, 107, 111, 112, 113, $114,115,116,119,178,180,181,182$, 183, 184, 266, 292

Artikulator 160

Aspekt 5, 11, 12, 14, 15, 16, 18, 32, 35, 36, 37, $38,39,40,41,42,43,44,45,46,47$, $48,49,50,52,55,58,59,60,61,63$, $64,67,68,69,72,74,75,78,79,80$, $82,85,87,90,93,94,95,98,99,100$, $101,102,106,120,122,124,125,126$, $129,131,132,135,137,138,153,154$, $155,156,161,162,167,168,169,171$, 172, 186, 189, 190, 191, 192, 193, 194 , 195, 196, 199, 201, 202, 203, 205, 208, $214,215,218,219,222,223,224,225$, 226, 228, 229, 230, 231, 232, 233, 234, 235, 236, 238, 239

Aspekterwerb 40, 60, 199

Aspektmarkierer 11, 12, 36, 39, 40, 50, 53, 54, 61, 99, 129

Aspektmarkierung 89, 94, 99, 100, 124, 152, 199, 223, 224, 225, 226, 227, 233, 234, 235

Aspektsprachen 100,101, 109, 110, 111, 112, $114,115,116,118,119,120,121,122$, 125, 126, 132, 162, 168, 190, 201, 231

Aspektsystem 14, 15, 16, 17, 19, 35, 36, 40, $43,46,49,51,59,61,63,65,82,83,85$, $91,98,99,100,101,114,120,126,127$, $137,154,167,170,172,185,190,191$, 202, 218, 219, 231, 238, 239

Aufmerksamkeit 14, 17, 20, 21, 49, 94, 95, $96,97,98,102,106,111,119,120,122$, $125,126,127,128,129,130,131,132$, $134,137,167,172,178,180,184,185$, 238, 242

Automatisierung 20, 159, 161, 163, 164, 166, 185,243

Baseline 220

Beherrschungsgrad 157, 158, 165, 239
Bewegungsereignis $7,16,17,18,52,63,65$, $68,75,83,86,87,88,89,95,96,97$, $98,99,100,101,102,105,106,108$, $109,111,120,121,124,125,126,127$, $128,130,131,132,134,135,136,137$, $138,139,140,141,142,144,145,146$, $147,152,154,155,156,158,161,162$, $165,166,167,168,169,170,171,172$, $174,175,178,180,182,184,185,186$, $187,188,209,241$

Bilingualismus $6,7,90,156,159,163,164$, $165,166,245$

Code-Switching 8,164

Denken 3, 9, 10, 11, 14, 130, 157, 158, 242

Ein-Zustand-Verben 38, 41, 56, 57

Elizitation 4, 15, 16, 17, 18, 19, 20, 22, 23, 91, $100,106,134,144,158,168,187,188$, 220, 292

Endpunkt 13, 17, 21, 41, 42, 43, 49, 51, 52, 54, 57, 63, 83, 86, 87, 88, 89, 97, 100, $102,106,109,110,111,112,116,119$, $120,122,125,126,127,128,132,135$, $136,139,140,141,142,143,144,145$, $147,150,152,153,162,167,170,171$, $172,174,175,176,177,179,180,182$, 183, 184, 185, 191, 208, 209, 210, 211, 212, 213, 214

Endpunktmarkierung 86, 136, 139, 140, $141,142,143,144,145,146,147,148$, $151,153,155,196,198,202,210,212$, 214

Endzustand 11, 19, 157, 163, 189, 219, 223, 227, 229, 231, 236, 237

Ereignisenkodierung 15, 18, 90, 107, 189, 190, 215, 241, 244

Ereigniskonzeptualisierung 4, 6, 12, 16, 51, 93, 95, 97, 98, 120, 124, 127, 132, 137, $158,160,161,171,215$

Ereignisversprachlichung $51,61,64,100$, $102,124,130,134,138,188,196$, 206

Erstspracherwerb 38, 159, 200, 220, 221

Ә Open Access. (C) 2018 Mertins, publiziert von De Gruyter. (œ) Er-NC-ND Dieses Werk ist lizenziert unter der Creative Commons Attribution-NonCommercial-NoDerivatives 4.0 Lizenz. https://doi.org/10.1515/9783110615746-014 
Eye-Tracking 4, 20, 21, 49, 93, 95, 97, 103, $106,108,111,112,119,125,126,158$, $159,162,174,177,180$

Fixation $21,97,107,108,111,112,113,114$, $115,116,117,118,119,120,128,178$, $180,181,182,183,184$

Formulator 93, 94, 160

Gedächtnisleistung 4, 16, 17, 19, 93, 106, $121,122,125,130,134,136,152,176$, 177, 185, 187, 188, 241

Grammatische Kategorie 10, 15, 40, 41, 43, $46,127,135,167,185,222,233$

Grammatischer Aspekt 11, 14, 35, 36, 40, 44, 125, 137, 189, 192, 196, 202, 213, 226

Habitualität 12, 40, 42, 137

Hier-und-jetzt-Bedeutung 15, 52, 64, 65, 67, $72,73,74,75,76,77,78,79,82,83,84$, 138, 139, 186, 204, 213

Holistische Perspektive 17, 40, 83, 84, 89, $97,132,135,136,138,139,140,151$, 153, 154, 156, 168, 171, 172, 175, 241

Imperfektiva 64, 75, 83, 137, 193, 203, 204, 205, 213

Imperfektivität $12,15,35,39,40,41,43,44$, $45,46,47,48,49,51,52,53,58,59,61$, $64,67,68,75,79,81,82,83,85,94$, $98,99,100,101,102,126,132,137,154$, $168,170,171,172,191,193,199,203$, 205

Kognitives Profil 157, 158, 164, 186, 245

Kompetenz 9, 22, 36, 69, 157, 187, 243, 244

Konzeptualisierer 93, 159, 160

Korpusanalyse 5, 23, 81, 82, 133, 217, 228, 245

Kritische Stimuli 68, 74, 86, 105, 142

Linguistische Analysen 4, 7, 136

linguistische Relativität 9

Lokale Angaben 196, 197, 209, 211, 212

Multilingualismus 6, 7, 8, 145, 244
Nicht-sprachliche Aufgaben 5, 96, 135, 158, 165, 187, 188, 242

Null-Zustand-Verben 37, 56

Objektbenennung 244

Offline-Methode 19, 22

Online-Methode 19, 20, 22

Perfektivität 15, 35, 39, 41, 42, 43, 44, 45, $46,47,48,51,52,60,61,67,83,101$, $153,167,171,186$

Perspektivenwahl 4, 15, 53

Präferenz 6, 11, 13, 14, 15, 16, 18, 22, 23, 36, $46,50,51,52,53,59,60,61,63,70,75$, $83,86,88,95,96,97,98,106,109$, $122,124,129,130,131,135,136,137$, $138,145,147,148,152,153,154,161$, $162,166,167,168,171,172,175,178$, $180,185,186,194,198,202,204,205$, 208, 210, 211, 213, 214, 215, 223, 226, 229, 231, 232, 233, 237, 238, 241, 242, 243, 244

Präferenzmuster 51, 52, 53, 59, 60, 95, 120 , $127,129,161,166,182,183,184,188$, $189,192,243$

Präferenztest $22,65,73,74,78,80$

Präfigierung 45, 46, 47, 63, 64, 67, 68, 79, 137, 138, 144, 191, 193, 195, 196, 197, 203, 204, 205, 207, 208, 211, 212, 213, 229

Priming 44, 105

Progressivität $15,39,40,42,43,46,49,53$, $55,57,58,59,60,61,98,99,100,101$, $102,120,126,129,132,167,222,225$, 234

Psycholinguistik 3, 4, 7, 9, 10, 15, 20, 21, 36, $49,50,82,90,95,130,131,157,158$, 163, 164, 214, 218, 238, 243

Psychotypologie 19, 218, 244

Repräsentation $6,51,96,100,131,152,158$, $159,161,242,243$

Restrukturierung $6,7,22,159,164,165,166$, $186,187,188,243,244,245$

Sakkade 21, 108, 179

Saphir-Whorf-Hypothese 3,10 
Seeing for Speaking 14, 17, 94, 127, 130, 242

Selektion 4, 93, 100, 124, 127, 129, 130, 134, 154, 160, 190, 198, 214, 239, 241

Sprache $3,4,5,8,9,10,11,12,13,14,16,17$, $18,20,21,26,28,31,32,41,43,49,50$, 52, 94, 105, 110, 112, 114, 115, 116, 117, $118,129,130,131,132,133,134,138$, $145,152,161,164,166,167,168,172$, 173, 176, 177, 186, 187, 215, 221, 238, 243

Spracherwerbsmuster 39

Sprache und Kognition 3, 5, 9, 18, 130, 135, 215, 242

Sprachfamilien 217, 221, 241

- Germanische Sprachfamilie 221

- Ostslawische Sprachfamilie 16, 17, 82, 85, 91, 101, 138, 221

- Westslawische Sprachfamilie 80,82 , $85,89,90,91,101,138,217,221$

Sprachkontakt 4, 5, 7, 8, 15, 16, 19, 25, 32, $33,82,84,89,90,91,133,155,185$, 239, 245, 246

Sprachliche Aufgabe 49, 95

Sprachproduktion $4,6,7,11,14,16,21,36$, $49,51,52,53,59,61,73,75,77,80,93$, 94, 95, 96, 102, 103, 106, 108, 119, 121, $125,127,129,133,134,138,155,156$, $157,158,159,160,168,171,173,174$, $179,182,184,185,189,201,202,214$, 221, 243

Sprachrezeption 21, 159, 187
Sprachvergleich 1, 5, 23, 35, 46, 49, 51, 59, 61, 95, 120, 159, 178, 186, 191, 196, 201, 202, 217

Sprechanfangszeit $4,13,19,49,50,134$, 135, 136, 266

Strukturierung 4, 14, 35, 127, 130, 160, 161, 166, 185, 186, 201, 202

Telizität 15, 35, 41, 42, 43, 61

Tempusmarkierung 43

Thinking for Speaking 10, 94, 98, 124, 127, 134, 242

Topikzeit 37, 38, 192, 195, 205

Trajektoriemarkierung 88, 143, 145, 148, 152

Verarbeitungsgrad 243

Verbaltyp 35, 55, 56, 57, 99, 193, 194, 195

Verlaufsmarkierung 43, 168

Verlaufsperspektive $13,88,135,136,138$, 172, 175, 241

Voraktivierung 6, 243

Zeitdruck-Paradigma 14, 17, 20, 23, 89, 133 , 134, 139, 140, 141, 145, 149, 151, 152, 153, 154, 155, 156

Zweitspracherwerb 6, 17, 18, 35, 36, 46, 61, $157,159,162,163,164,165,166,189$, 190, 198, 199, 200, 208, 212, 218, 219, 220, 221, 222, 223, 226, 227, 228, 229. 230, 231, 232, 233, 234, 235, 236, 237, 238, 239

Zwei-Zustand-Verben 38, 56 
